\title{
Combined aberrant expression of E-cadherin and S100A4, but not $\beta$-catenin is associated with disease-free survival and overall survival in colorectal cancer patients
}

Sang-Jeon Lee ${ }^{1}$, Song Yi Choi ${ }^{2}$, Wun-Jae Kim³ ${ }^{3}$, Meiying Ji ${ }^{4}$, Taek-Gu Lee ${ }^{1}$, Bo-Ra Son ${ }^{5}$, Soon Man Yoon ${ }^{4}$, Rohyun Sung ${ }^{2}$, Eun Jeoung Lee ${ }^{4}$, Sei Jin Youn ${ }^{4}$ and Seon Mee Park ${ }^{4^{*}}$

\begin{abstract}
Background/Aims: Epithelial-to-mesenchymal transition (EMT) in cancers is related to metastasis, recurrence, and poor prognosis. We evaluated whether EMT-related proteins can act as prognostic biomarkers in colorectal cancer (CRC) patients.
\end{abstract}

Methods: We evaluated the expression of E-cadherin, $\beta$-catenin, and S100A4 by immunohistochemistry (IHC) in 333 CRC tissues from the tumor center and invasive margin. Tumor budding, cell grade, tumor stage, type of tumor growth, peritumoral lymphocyte infiltration (TLI), and perineural- or lymphovascular invasion were evaluated as pathological parameters. mRNA levels of E-cadherin, N-cadherin, $\beta$-catenin, and S100A4 from 68 specimens from the same set were analyzed by real time quantitative RT-PCR.

Results: Loss of E-cadherin, nuclear $\beta$-catenin, and gain of S100A4 were higher in the invasive margin than in the tumor center. Loss of E-cadherin was associated with cell grade, macroscopic type, perineural invasion, and tumor budding, $\beta$-catenin with microsatellite instability and tumor site, and S100A4 with growth type, macroscopic type, AJCC stage, lymphovascular invasion, and perineural invasion. The aberrant expression of E-cadherin and S100A4 not $\beta$-catenin in the invasive margin was a significant and independent risk factor for disease-free and overall-survival by multivariate analysis, along with AJCC stage and perineural invasion. mRNA levels of $\beta$-catenin and S100A4 were correlated with the $\mathrm{HC}$ findings at the tumor invasive margin. E-cadherin and $\mathrm{N}$-cadherin showed a weak inverse correlation.

Conclusions: The combination of loss of E-cadherin and gain of S100A4 in the tumor invasive margin can be used to stratify patients with the same AJCC stage into different survival groups.

Virtual slides: The virtual slides for this article can be found here: http://www.diagnosticpathology.diagnomx.eu/ vs/9398289629244673

Keywords: Epithelial to mesenchymal transition, E-cadherin, $\beta$-catenin, S100A4, Tumor budding, Colorectal cancer

\section{Background}

The incidence of colorectal cancers (CRC) has been increasing in Korea since 1999. In 2009, CRC was the fourth most fatal cancer [1]. Although the 5-year survival rate of CRC overall has been reported to be as high as $71.3 \%[1]$, the survival rate in patients with recurrence is only $40 \%$

\footnotetext{
* Correspondence: smpark@chungbuk.ac.kr

${ }^{4}$ Department of Internal Medicine, Chungbuk National University College of Medicine and Medical Research Institute, Cheongju, Republic of Korea Full list of author information is available at the end of the article
}

[2]. The recurrence rate of stage I - III CRC patients who received curative resection has been reported to be $27.3 \%$ [2]. In addition to American Joint Committee on Cancer (AJCC) stage, biomarkers to predict recurrence are needed to select those patients who should be treated more aggressively. The growth pattern of the invasive margin, tumor budding, tumor grade, perineural invasion, and lymphovascular invasion have been reported to predict a poor prognosis $[3,4]$. Tumor buds are thought to be responsible for the subsequent steps in invasion and metastasis [5].

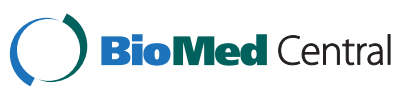


They are considered the histological hallmark of the epithelial to mesenchymal transition (EMT) [6].

EMT is the process by which mature epithelial cells change in appearance and lose cell-cell contacts and epithelial protein expression while at the same time acquiring the phenotypic characteristics of mesenchymal cells [7]. Many different EMT-related proteins and transcriptional factors that promote tumor progression and local or distant metastasis have been reported. Immunohistochemical staining (IHC) of human tissues obtained from patients with CRC demonstrated that the loss or attenuation of epithelial marker expression and the gain of mesenchymal marker expression are closely related to tumor progression and poor prognosis.

The initial step in tumor invasion and metastasis is the break-up of adhesion junctions mediated by E-cadherin, resulting in extension of the tumor cells into the stroma and their attachment to the extracellular matrix. Loss of E-cadherin in CRC correlates with clinicopathologic features of aggressive CRC and predicts poor prognosis [8]. Dysfunction of the Wnt-signaling pathway plays an important role in colorectal carcinogenesis and Wnt signaling dysfunction leads to the nuclear accumulation of $\beta$-catenin [9]. Nuclear translocation of $\beta$-catenin triggers an EMT and a proinvasive gene expression [10]. Nuclear $\beta$-catenin expression has been observed in advanced CRC, but the prognostic significance was not clarified; it was related to poor prognosis [11], no effect $[9,12]$ or even favorable prognosis [13]. S100A4 is directly involved in the formation of metastasis from several different tumor types via increased cell motility and invasion [14]. In CRC, nuclear expression of this protein is related to advanced tumor stage [15] and poor metastasis-free and overall survival [16]. EMT-related proteins such as E-cadherin, $\beta$-catenin, and S100A4 are known to be related to carcinogenesis and tumor progression, but the relation of these protein expressions and whether these proteins can serve as prognostic biomarkers of CRC were not clarified.

The aim in this study was to evaluate whether EMTrelated protein expression and clinicopathological features of CRC are useful prognostic predictors or not. We compared the patterns of EMT protein expression in the tumor center and invasive margin and determined if there were correlations between the IHC findings and mRNA expression levels of various EMT-related genes.

\section{Methods}

\section{Patients and tissue samples}

Paraffin-embedded tissues were obtained from the department of pathology and fresh frozen specimens were provided by the National Biobank of Korea, with the approval of the Ethics Committee of Chungbuk National University Hospital. Three hundred thirty-three CRC patients (male:female, 189:144), who underwent complete resection (R0) and were followed-up for more than 5 years were enrolled in this study. The patients did not receive any chemotherapy or radiation therapy before surgery. Among the enrolled patients, 68 fresh-frozen specimens were obtained for real time RT-PCR. At the time of surgery, tumor tissues and matched normal tissues were immediately sampled from the resected colorectal specimen by pathologists. The tissue was frozen in liquid nitrogen, and kept at $-80^{\circ} \mathrm{C}$.

\section{Histopathology}

Each tumor was re-evaluated by analysis of the medical records and the tissue slide files by one pathologist. Tumor location (right side or left side), the degree of differentiation (well, moderately, and poorly), depth of tumor invasion, lymph node or distant metastasis, and microsatellite status (characterized in 166 cases) were assessed. The stages were defined according to the TNM staging system of AJCC. We also reviewed macroscopic type (polypoid, ulcerofungating, and ulceroinfiltrative), invasion to the lymphatics or vessels, and perineural invasion. Tumor growth was classified as expanding- or infiltrative-type and tumor budding was evaluated by cytokeratin staining. The number of tumor buds was counted in five regions of clusters of tumor cells comprising less than 5 cells at 200x magnification. We divided cases into those with low (median $<10$ ) or high budding (median $\geq 10$ ) (Figure 1 ).

\section{Tissue microarray (TMA) construction and immunohistochemistry (IHC)}

After all slide reviews, 3-mm sized TMAs were constructed. Areas from the center and the invasive margin of the tumor with the lowest degree of differentiation but abundant in cells with high mitotic activity were chosen from the original blocks. These representative areas were marked by an experienced pathologist on hematoxylin and eosin (H\&E)stained slides from selected paraffin blocks. Serial 4-um sections were then cut from the TMA paraffin blocks. The sections were mounted on Capillary Gap plus Slides. Before IHC staining, all sections were deparaffinized and heated in citrate buffer ( $10 \mathrm{mM} / \mathrm{L}$ citric acid, $\mathrm{pH}$ 6.0) in a microwave oven. After inactivation by exposure to $3 \%$ $\mathrm{H}_{2} \mathrm{O}_{2}$ for $10 \mathrm{~min}$, the sections were incubated with blocking serum at room temperature for $10 \mathrm{~min}$. IHC staining was carried out using anti-E-cadherin (DakoCytomation, Glostrup, Denmark, 1:400), anti-cytokeratin (LeicaMicro systems, Wetzlar, Germany, 1:300), anti- $\beta$-catenin (Dako Cytomation, Glostrup, Denmark, 1:400) and anti-S100A4 (DakoCytomation, Glostrup, Denmark, 1:800) as primary antibodies. After incubation with secondary antibodies, the expression of these markers in cells was detected with diaminobenzidine (DAB; Sigma, St. Louis, MO, USA) by enhancement with a SABC kit (ZSGB-BIO, Beijing, China). Tissue sections stained without primary antibody 

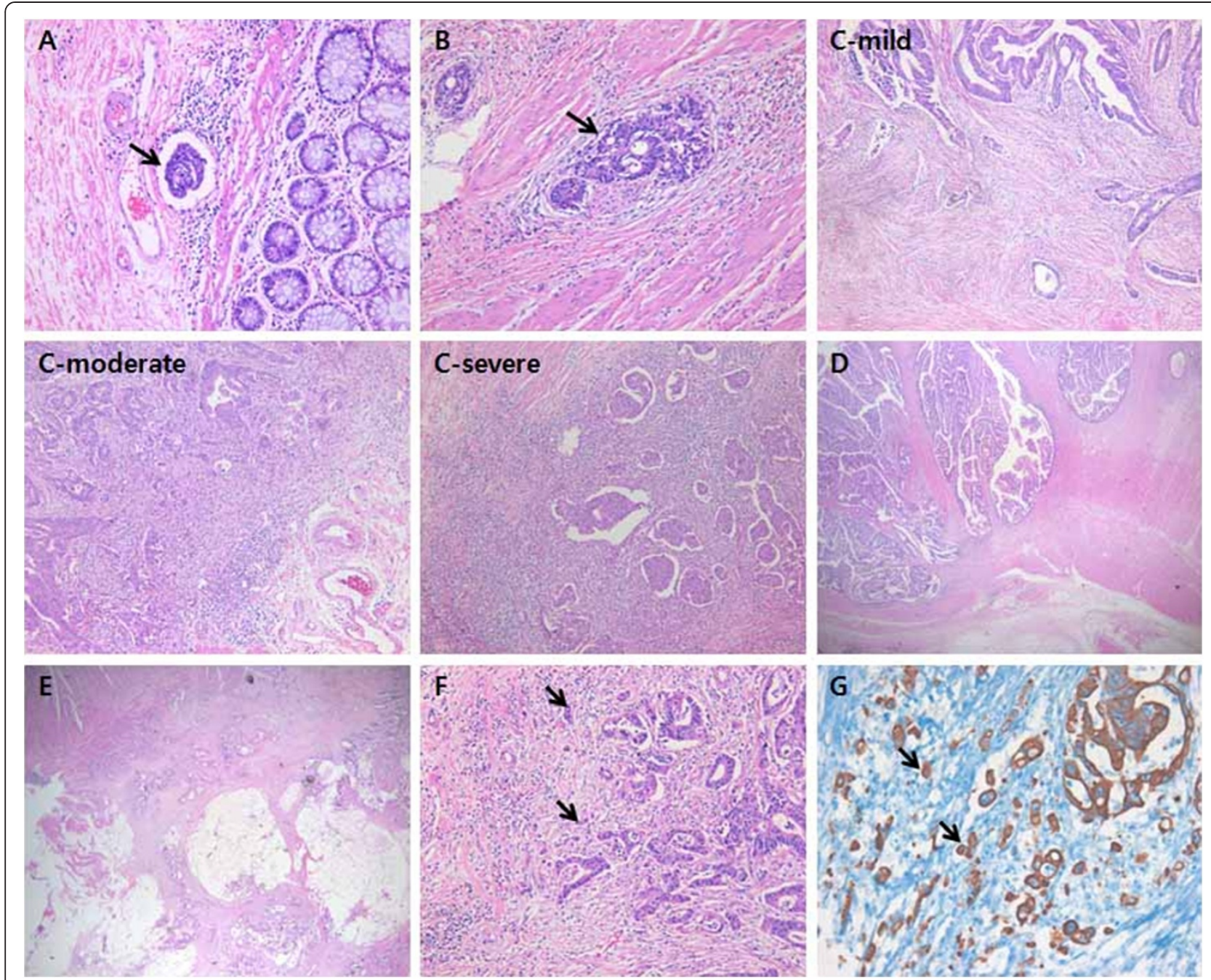

Figure 1 Representative pathologic features of colorectal cancer. Lymphovascular invasion (A), perineural invasion (B), lymphocyte infiltration (mild, moderate, and severe) (C), and type of tumor growth (expanding $\mathbf{D}$ and infiltrative $\mathbf{E}$ ). High tumor budding at the invasive margin stained with hematoxylin and eosin (F) and cytokeratin expression (G).

served as a negative control. The slides were then counterstained with hematoxylin. The results were assessed by two pathologists who were blinded to the patients' details. E-cadherin immunostaining was evaluated according to a method described previously [17]. E-cadherin staining was classified as grade 0 (preserved) when more than $90 \%$ of the CRC cells on a section showed strong membranous staining, or grade 1 (reduced or lost) when less than $90 \%$ of the CRC cells showed positive membranous staining. For $\beta$-catenin, the percentage of tumor cells with nuclear staining was evaluated and scored as grade $0(0-30 \%)$ or grade 1 (30-100\%). To evaluate S100A4 expression, staining intensity was recorded as 0 (no staining), 1 (weak staining), 2 (intermediate staining), or 3 (strong staining). The proportion of stained cells was expressed as a percentage. The staining score was obtained by multiplying the intensity and percentage of stained cells and classified as grade 0 (low expression) and grade 1 (high expression) (Figure 2).

\section{Real time quantitative RT-PCR of EMT related genes}

Tumor and matched normal tissues were homogenized and total RNA was isolated using an RNeasy Mini kit (Qiagen, Tokyo, Japan) following the manufacturer's instructions. All samples were treated with RNase-free DNase (Qiagen). RNA quality control and quantification were carried out on an Agilent 2100 Bioanalyzer using a RNA 6000 Pico LabChip (Agilent Technologies, Tokyo, Japan). Firststrand complementary DNA was made from total RNA using the Prime Script RT-reagent kit (Amersham Biosciences Europe $\mathrm{GmbH}$, Freiburg, Germany) according to the manufacturer's instructions. To quantify the expression levels of E-cadherin, $\beta$-catenin, $\mathrm{N}$-cadherin, and S100A4, real-time PCR amplification was performed 


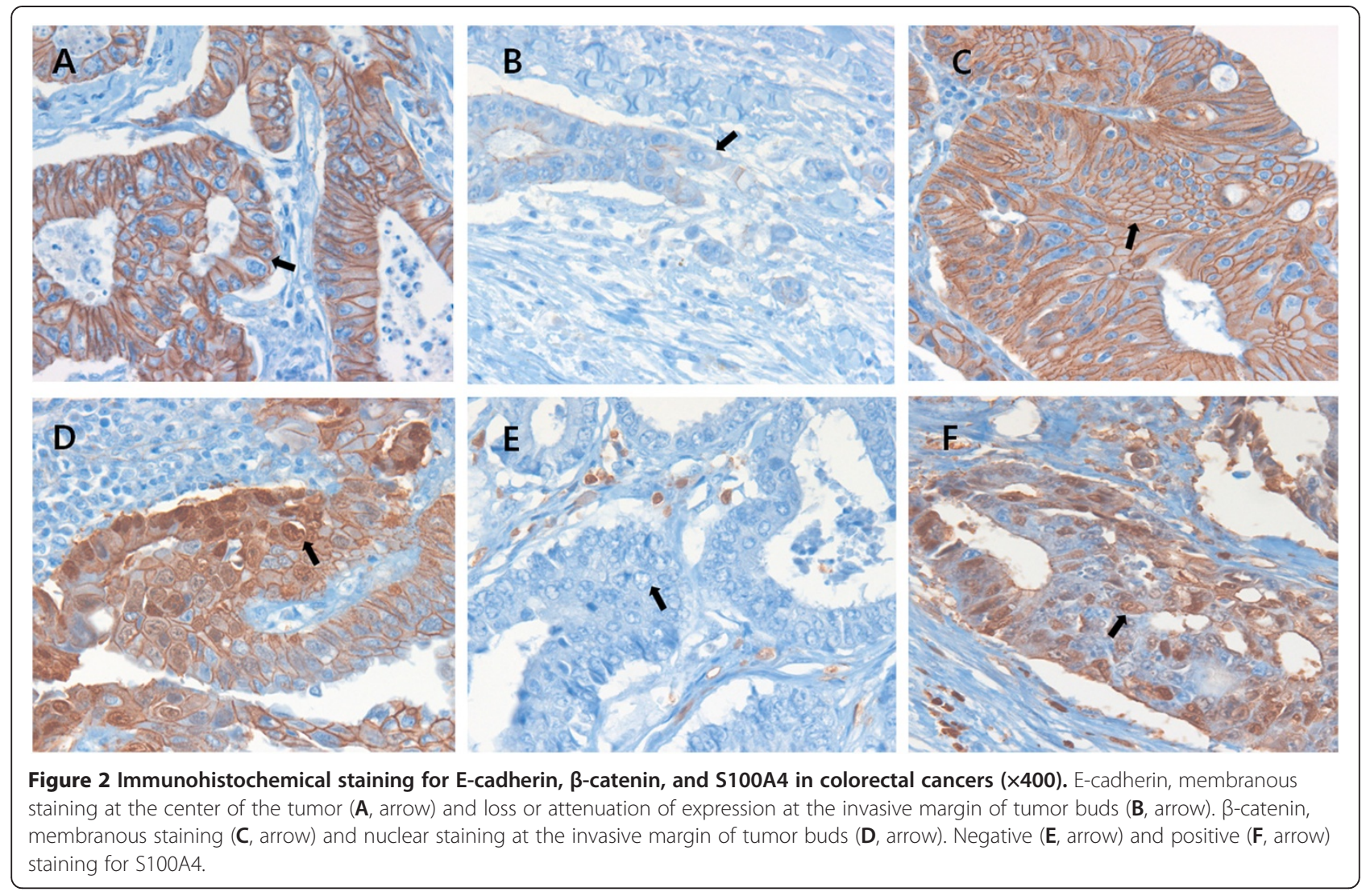

with a Rotor Gene 6000 instrument (Corbett Research, Mortlake, Australia). Real-time PCR assays using SYBR Premix EX Taq (TAKARA BIO INC., Otsu, Japan) were carried out in micro-reaction tubes (Corbett Research, Mortlake, Australia). The PCR reaction was performed in a final volume of $10 \mu \mathrm{l}$, consisting of $5 \mu \mathrm{l}$ of $2 \mathrm{x}$ SYBR premix EX Taq buffer, $0.5 \mu \mathrm{l}$ of each 5'- and 3'- primer $(10 \mathrm{pmol} / \mu \mathrm{l})$, and $1 \mu \mathrm{l}$ of sample cDNA. The product was 10 -fold serially diluted from $100 \mathrm{pg} / \mu \mathrm{l}$ to $0.1 \mathrm{pg} / \mu \mathrm{l}$. Dilution series of PCR products were used to establish standard curves for real-time PCR. Spectral data were captured by using Rotor-Gene Real-Time Analysis Software 6.0 Build 14 (Corbett Research, Mortlake, Australia). All samples were run in triplicate. Glyceraldehyde-3phosphate dehydrogenase (GAPDH) was used as an endogenous RNA reference gene. Gene expression was normalized to the expression of GAPDH. Primers and product sizes for E-cadherin, $\mathrm{N}$-cadherin, $\beta$-catenin, S100A4, and GAPDH are summarized in Table 1.

\section{Statistical analysis}

Differences were compared using Fisher's exact test or Pearson's test for qualitative variables and Student's t-test or analysis of variance for continuous variables. Prognosis was determined by disease-free survival and overall survival. Prognostic factors were examined by univariate and multivariate analyses (Cox proportional hazards model). All statistical tests were two sided, and statistical significance was accepted at the $\mathrm{P}<0.05$ level. All analyses were performed using SPSS version 12.0 (SPSS Inc., Chicago, IL, USA).

Table 1 Sequences of primers and product size used in real time RT-PCR

\begin{tabular}{llll}
\hline Gene & \multicolumn{1}{c}{ Forward } & Backward & size \\
\hline E-cadherin & AGTCACGCTGATACAGTGG & CATTTCTGGGCAGCTGATG & 161 \\
N-cadherin & CAGTGCAGTCTTATCGAAGG & GAAAGCTTCTCACGGCATAC & 158 \\
$\beta$-catenin & AATGGCAGTGCGTTAGCTG & ATAGCACCTTCAGCACTCTG & 233 \\
S100A4 & CACAAGTACTCGGGCAAAGA & TACACATCATGGCGATGCAG & 211 \\
GAPDH & TGAGAACGGGAAGCTGTCA & GGAAGGCCATGCCAGTGA & 258 \\
\hline
\end{tabular}




\section{Results}

\section{Clinicopathologic parameters related to EMT-related protein expression}

Clinicopathologic characteristics of the patients showed in Table 2. The relation between clinicopathological parameters and aberrant expression of E-cadherin, $\beta$-catenin and S100A4 in the invasive margin was observed. Loss of E-cadherin was related with cell grade $(\mathrm{p}=0.050)$, macroscopic type $(\mathrm{p}=0.014)$, perineural invasion $(\mathrm{p}=0.037)$ and high tumor budding $(p=0.010)$. Nuclear $\beta$-catenin expression was higher in microsatellite stable (MSS) than microsatellite instable (MSI) tumors $(p=0.004)$ and left CRCs than in right CRCs $(\mathrm{p}=0.037)$. S100A4 expression was increased in infiltrative growth $(\mathrm{p}=0.017)$, macroscopic type $(p=0.024)$, T-stage $(p=0.010)$, nodal stage $(p=0.002)$, AJCC stage $(p=0.001)$, ratio of metastatic lymph nodes $(\mathrm{p}=0.019)$, lymphovascular invasion $(\mathrm{p}=0.034)$, and perineural invasion $(p=0.050)$. It was also related with TLI $(\mathrm{p}=0.001)$ (Table 3$)$.

\section{Relation of E-cadherin, $\beta$-catenin and S100A4 expression}

The aberrant expression of EMT-related proteins was higher in the invasive margin than in the tumor center; loss of E-cadherin, $17.9 \%$ versus $31.8 \%$ ( $\mathrm{p}<0.0001$ ), nuclear expression of $\beta$-catenin, 10.6\% versus $12.5 \%(\mathrm{p}<0.0001)$, and gain of S100A4, 10.2\% versus 15.5\% ( $<<0.0001$ ), respectively. Aberrant expression of each protein was related to the others: S100A4 versus E-cadherin $(r=0.312$, $\mathrm{p}=0.050), \mathrm{S} 100 \mathrm{~A} 4$ versus $\beta$-catenin $(\mathrm{r}=0.166, \mathrm{p}=0.004)$ and $\mathrm{E}$-cadherin versus $\beta$-catenin $(\mathrm{r}=0.152, \mathrm{p}=0.009)$.

Prognostic factors of disease-free survival and overall survival Disease-free survival was associated with AJCC stage ( $\mathrm{p}<$ 0.0001 , Figure $3 \mathrm{~A})$, tumor budding $(\mathrm{p}=0.007$, Figure $3 \mathrm{~B})$, tumor growth type $(p=0.003$, Figure $3 C)$, and perineural invasion $(p=0.004$, Figure $3 \mathrm{D})$. Aberrant expression of the E-cadherin $(p=0.007$, Figure 3E), S100A4 $(p=0.004$, Figure $3 \mathrm{~F}$ ), and combination of both proteins in the invasive margin were related to disease free survival $(\mathrm{p}=0.005$, Figure $3 G)$, whereas $\beta$-catenin was inversely related $(\mathrm{p}=0.032$, Figure $3 \mathrm{H})$. Multivariate Cox analysis showed that combination of E-cadherin and S100A4 expressions in the invasive margin and the AJCC stage are independent risk factor for disease-free survival (Table 4). Overall survival was associated with AJCC stage $(\mathrm{p}<0.0001$, Figure $4 \mathrm{~A})$, tumor budding ( $\mathrm{p}=0.01$, Figure $4 \mathrm{~B})$, tumor growth type $(p=0.01$, Figure $4 C)$, perineural invasion $(p=0.02$, Figure 4D), and TLI $(p=0.005$, Figure $4 E) . A b-$ errant expression of E-cadherin $(p=0.002$, Figure $4 F)$, S100A4 ( $p=0.003$, Figure $4 \mathrm{G}$ ), and combination of both proteins in the invasive margin were associated with overall survival time $(p=0.0002$, Figure $4 \mathrm{H})$, whereas $\beta$-catenin was not. Cox regression analysis showed that the combination of E-cadherin and S100A4 in the
Table 2 Clinical and pathological characteristics of 333 patients with colorectal cancers

\begin{tabular}{|c|c|}
\hline Characteristics & N (\%) \\
\hline Age (years), Mean \pm SD (range) & $63.6 \pm 11.1(25-86)$ \\
\hline \multicolumn{2}{|l|}{ Gender } \\
\hline Male & $189(56.8)$ \\
\hline Female & $144(43.2)$ \\
\hline \multicolumn{2}{|l|}{ Tumor Grade } \\
\hline Well & $77(23.1)$ \\
\hline Moderately & $236(70.9)$ \\
\hline Poorly & $11(3.3)$ \\
\hline Undetermined & $9(2.7)$ \\
\hline \multicolumn{2}{|l|}{ Depth of Invasion } \\
\hline $\mathrm{T} 1$ & $13(3.9)$ \\
\hline $\mathrm{T} 2$ & $43(12.9)$ \\
\hline T3 & $210(63.1)$ \\
\hline T4 & $67(20.1)$ \\
\hline \multicolumn{2}{|l|}{ Nodal Stages } \\
\hline No & $195(58.6)$ \\
\hline $\mathrm{N} 1(\mathrm{a}, \mathrm{b})$ & $86(25.8)$ \\
\hline $\mathrm{N} 2(\mathrm{a}, \mathrm{b})$ & $52(15.6)$ \\
\hline \multicolumn{2}{|l|}{ AJCC stage } \\
\hline 1 & $44(13.2)$ \\
\hline$\|$ & $143(42.9)$ \\
\hline III & $119(35.7)$ \\
\hline IV & $27(8.1)$ \\
\hline \multicolumn{2}{|l|}{ Lymphovascular Invasion } \\
\hline Negative & $240(72.1)$ \\
\hline Positive & $93(27.9)$ \\
\hline \multicolumn{2}{|l|}{ Perineural invasion } \\
\hline Negative & $306(91.9)$ \\
\hline Positive & $27(8.1)$ \\
\hline \multicolumn{2}{|l|}{ Lymphocyte infiltration } \\
\hline Mild & $112(33.6)$ \\
\hline Moderate & $170(51.1)$ \\
\hline Severe & $45(13.5)$ \\
\hline \multicolumn{2}{|l|}{ Type of Tumor Growth } \\
\hline Expanding & $118(36.3)$ \\
\hline Infiltrative & $207(62.2)$ \\
\hline Undetermined & $8(2.4)$ \\
\hline \multicolumn{2}{|l|}{ Tumor budding } \\
\hline Yes & $44(13.2)$ \\
\hline No & 289 (86.8) \\
\hline
\end{tabular}


Table 3 Relation between clinico-pathological parameters and immunohistochemistry of E-cadherin, $\beta$-cadherin, and S100A4 at invasive margin in colorectal cancers $(n=305)$

\begin{tabular}{|c|c|c|c|c|c|c|c|c|c|}
\hline \multirow[t]{2}{*}{ Parameters } & \multicolumn{2}{|c|}{ E-cadherin } & \multirow[t]{2}{*}{$\mathbf{P}$} & \multicolumn{2}{|c|}{$\beta$-cadherin } & \multirow[t]{2}{*}{$\mathbf{P}$} & \multicolumn{2}{|c|}{ S100A4 } & \multirow[t]{2}{*}{$P$} \\
\hline & $\begin{array}{c}\text { Strong } \\
(n=208)\end{array}$ & $\begin{array}{c}\text { Weak or Loss } \\
\quad(n=97)\end{array}$ & & $\begin{array}{c}\text { Nuclear, Low } \\
(n=267)\end{array}$ & $\begin{array}{c}\text { Nuclear, High } \\
(n=38)\end{array}$ & & $\begin{array}{c}\text { Low } \\
(n=267)\end{array}$ & $\begin{array}{c}\text { High } \\
(n=267)\end{array}$ & \\
\hline Preoperative CEA (ng/ml) & $7.0 \pm 22.5$ & $6.5 \pm 12.4$ & 0.811 & $6.5 \pm 19.8$ & $8.4 \pm 18.3$ & 0.573 & $5.3 \pm 13.1$ & $12.5 \pm 35.7$ & 0.014 \\
\hline MSI status $(n=166)$ & & & 0.167 & & & 0.004 & & & 0.386 \\
\hline MSI-H $(n=8)$ & $3(37.2)$ & $5(62.5)$ & & $8(100.0)$ & $0(0.0)$ & & $7(87.5)$ & $1(12.5)$ & \\
\hline MSI-L $(n=6)$ & $3(50.0)$ & $3(50.0)$ & & $4(66.7)$ & $2(33.3)$ & & $5(83.3)$ & $1(16.7)$ & \\
\hline MSS $(n=135)$ & $91(67.4)$ & $44(32.6)$ & & 107(81.1) & 25(18.9) & & $107(80.5)$ & $26(19.5)$ & \\
\hline Tumor Location & & & 0.455 & & & 0.037 & & & 0.704 \\
\hline Right $(n=66)$ & $48(72.7)$ & $18(27.3)$ & & \multicolumn{2}{|c|}{${ }^{*} 6.5 \pm 18.7$} & & $60(87.0)$ & $9(13.0)$ & \\
\hline Left $(n=236)$ & $158(66.9)$ & $78(33.1)$ & & \multicolumn{2}{|c|}{$* 12.2 \pm 22.7$} & & 194(84.0) & $37(16.0)$ & \\
\hline Tumor Budding & & & 0.011 & & & 0.799 & & & 0.480 \\
\hline Low $(<10)(n=263)$ & 188(70.9) & $77(29.1)$ & & $230(87.1)$ & $34(12.9)$ & & $224(85.2)$ & $39(14.8)$ & \\
\hline High $(\geq 10)(n=40)$ & $20(50.0)$ & $20(50.0)$ & & $37(90.2)$ & $4(9.8)$ & & $32(80.0)$ & $8(20.0)$ & \\
\hline Macroscopic Tumor Type & & & 0.616 & & & 0.909 & & & 0.038 \\
\hline Polypoid $(n=21)$ & 17(77.3) & $5(22.7)$ & & 18(85.7) & $3(14.3)$ & & $21(100.0)$ & $0(0.0)$ & \\
\hline Ulcerofungating $(n=160)$ & 109(66.9) & $54(33.1)$ & & 143(88.3) & 19(11.7) & & 138(86.3) & $22(13.8)$ & \\
\hline Ulceroinfiltrative $(n=122)$ & $82(68.3)$ & $38(31.7$ & & 106(86.9) & $16(13.1)$ & & $97(79.5)$ & $25(20.5)$ & \\
\hline Tumor Grade & & & 0.735 & & & 0.817 & & & 0.577 \\
\hline Well $(n=73)$ & $53(72.6)$ & $20(27.4)$ & & $64(86.5)$ & $10(13.5)$ & & $60(82.2)$ & 13(17.8) & \\
\hline Moderate or Poor $(n=227)$ & $151(66.5)$ & $73(34.0)$ & & 196(87.5) & $28(12.5)$ & & $191(85.3)$ & $33(14.7)$ & \\
\hline Ratio of Metastatic Lymph Node & $0.11 \pm 0.19$ & $0.13 \pm 0.21$ & 0.567 & $0.12 \pm 0.20$ & $0.09 \pm 0.19$ & 0.317 & $0.11 \pm 0.19$ & $0.18 \pm 0.23$ & 0.019 \\
\hline Nodal Stages & & & 0.567 & & & 0.288 & & & 0.002 \\
\hline No $(n=178)$ & 128(70.3) & $54(29.7)$ & & 155(85.2) & $27(14.8)$ & & $161(90.4)$ & $17(9.6)$ & \\
\hline$N 1(n=77)$ & 49(63.6) & $28(36.4)$ & & 69(92.0) & $6(8.0)$ & & $57(74.0)$ & $20(26.0)$ & \\
\hline$N 2(n=48)$ & $31(67.4)$ & $15(32.6)$ & & $43(89.6)$ & $5(10.4)$ & & $38(79.2)$ & 10(20.8) & \\
\hline Depth of Invasion & & & 0.513 & & & 1.000 & & & 0.010 \\
\hline$T 1, T 2(n=50)$ & $38(73.1)$ & $14(26.9)$ & & $44(88.0)$ & $6(12.0)$ & & 48(96.0) & $2(4.0)$ & \\
\hline T3, T4 $(n=253)$ & $170(67.2)$ & $83(32.8)$ & & $223(87.5)$ & $32(12.5)$ & & 208(82.2) & $45(17.8)$ & \\
\hline AJCC stage & & & 0.272 & & & 0.669 & & & 0.001 \\
\hline I $(\mathrm{n}=39)$ & $27(67.5)$ & $13(32.5)$ & & $35(87.5)$ & $5(12.5)$ & & $37(94.9)$ & $2(5.1)$ & \\
\hline$\|(n=133)$ & $96(71.1)$ & $39(28.9)$ & & $114(85.1)$ & $20(14.9)$ & & $119(89.5)$ & $14(10.5)$ & \\
\hline$\| I I(n=110)$ & $74(68.5)$ & $34(31.5)$ & & $97(89.8)$ & $11(10.2)$ & & $81(73.6)$ & $29(26.4)$ & \\
\hline IV $(n=21)$ & $11(50.0)$ & $11(50.0)$ & & 21(91.3) & $2(8.7)$ & & 19(90.5) & $2(9.5)$ & \\
\hline Lymphovascular Invasion & & & 0.891 & & & 0.341 & & & 0.050 \\
\hline Negative & $150(68.5)$ & $69(31.5)$ & & 195(88.6) & 25(11.4) & & 189(87.1) & 28(12.9) & \\
\hline Positive & $57(67.1)$ & 28(32.9) & & $72(84.7)$ & 13(15.3) & & $66(77.6)$ & $19(22.4)$ & \\
\hline Neural Invasion & & & 0.037 & & & 0.507 & & & 0.050 \\
\hline Negative & 196(69.8) & $85(30.2)$ & & 248(87.9) & $34(12.1)$ & & $240(85.7)$ & $40(14.3)$ & \\
\hline Positive & $11(47.8)$ & $12(52.2)$ & & 19(82.6) & $4(17.4)$ & & $15(68.2)$ & $7(31.8)$ & \\
\hline Lymphocyte infiltration & & & 0.325 & & & 0.821 & & & $<0.0001$ \\
\hline Mild & 70(72.9) & $26(27.1)$ & & $88(88.9)$ & 11(11.1) & & $70(71.4)$ & $28(28.6)$ & \\
\hline Moderate & 108(67.1) & $53(32.9)$ & & 138(86.3) & $22(13.8)$ & & 144(89.4) & 17(10.6) & \\
\hline Severe & $26(60.5)$ & $17(39.5)$ & & $36(87.8)$ & $5(12.2)$ & & $38(95.0)$ & $2(5.0)$ & \\
\hline
\end{tabular}


Table 3 Relation between clinico-pathological parameters and immunohistochemistry of E-cadherin, $\beta$-cadherin, and S100A4 at invasive margin in colorectal cancers $(n=305)$ (Continued)

\begin{tabular}{|c|c|c|c|c|c|c|}
\hline Type of Tumor Growth & & & & & 1.000 & \\
\hline Expanding & $79(73.1)$ & $29(26.9)$ & $93(87.7)$ & $13(12.3)$ & $96(90.6)$ & $10(9.4)$ \\
\hline Infiltrative & $125(65.1)$ & $67(34.9)$ & 168(87.0) & $25(13.0)$ & 156(81.3) & $36(18.8)$ \\
\hline
\end{tabular}

Lymph Node Ratio, number of metastatic lymph nodes / number of harvested lymph nodes; CEA carcinoembryonic antigen serum level, ${ }^{*}$, percentage of $\beta$-catenin nuclear expression at invasive margin.

invasive margin, the AJCC stage and perineural invasion were independent risk factors of overall survival time (Table 5).

\section{Association between mRNA expression and IHC findings}

Transcript levels of $\beta$-catenin and S100A4 were correlated with IHC findings at the tumor invasive margin; $\beta$-catenin $(\mathrm{r}=0.369, \mathrm{p}=0.003)$ and S100A4 $(\mathrm{r}=0.504, \mathrm{p}<0.0001)$. However, there was no relation between the RT-PCR data and the IHC findings for E-cadherin. E-cadherin and Ncadherin showed a weak inverse relation without statistical significance $(\mathrm{r}=-0.169, \mathrm{p}=0.084)$. mRNA levels of $\mathrm{N}$ cadherin were higher in recurrent or mortality cases $(\mathrm{p}=0.040$ and $\mathrm{p}=0.042$, respectively).

\section{Discussion}

In this study, we demonstrated that the combination of the loss of E-cadherin and gain of S100A4 in the invasive margin of $\mathrm{CRC}$ is an independent prognostic factor of a poorer outcome, along with AJCC stage and perineural invasion. Nuclear expression of $\beta$-catenin was not related to patient survival.
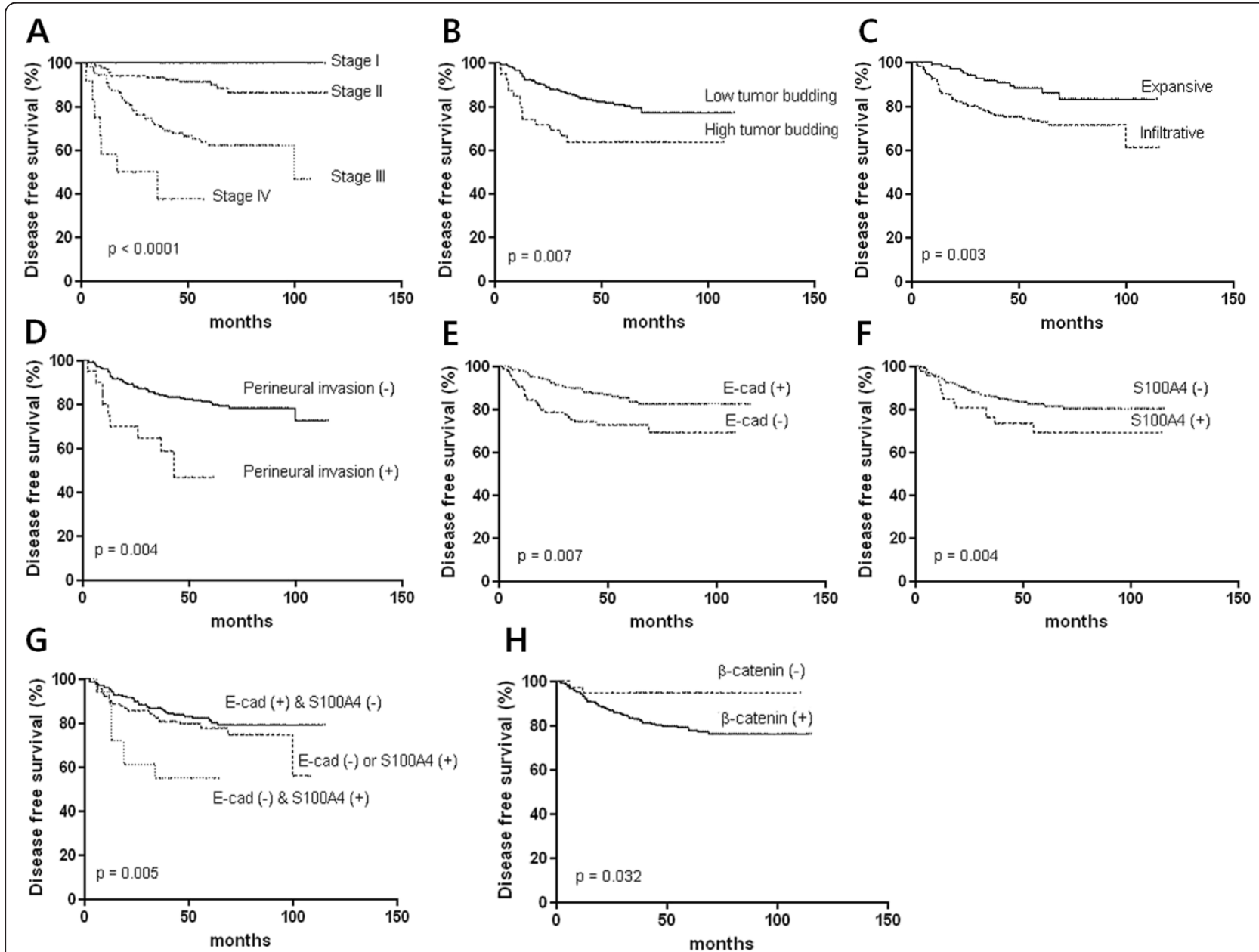

Figure 3 Analysis of disease free survival time according to histopathologic parameters and EMT related protein expression. AJCC stage (A), tumor budding (B), type of tumor growth $(\mathbf{C})$, Perineural invasion (D), E-cadherin expression (E), S100A4 expression (F), combination of E-cadherin and S100A4 (G), and $\beta$-catenin expression $(\mathbf{H})$. 
Table 4 Cox regression analysis for disease free survival time in colorectal cancers

\begin{tabular}{llll}
\hline Parameters & P value & Hazard Ratio & $\mathbf{9 5 \% ~ C l}$ \\
\hline *EMT, invasive front & 0.026 & 1.60 & $1.01-2.43$ \\
Lymphovascular invasion & 0.625 & 1.15 & $0.90-4.28$ \\
Perineural invasion & 0.092 & 1.96 & $0.90-4.28$ \\
Lymphocyte infiltration & 0.987 & 1.00 & $0.66-1.52$ \\
Tumor growth type & 0.306 & 1.43 & $0.72-2.85$ \\
Tumor budding ( $\geq 10 / \times 200 H P F)$ & 0.168 & 1.61 & $0.82-3.15$ \\
AJCC stage & 0.000 & 3.03 & $2.03-4.52$ \\
\hline
\end{tabular}

*EMT included the expressions of E-cadherin and S100A4.

When tumor cells start to invade and metastasize, adhesion molecules undergo alterations. Down-regulation of E-cadherin in CRC is associated with malignant features. Loss of E-cadherin has been shown to be associated with tumor budding [18] and lymph node metastasis in CRC [19] and to predict disease recurrence and long-term
Table 5 Cox multivariate analysis for overall survival time in colorectal cancers

\begin{tabular}{llll}
\hline Parameters & P value & Hazard Ratio & $\mathbf{9 5 \% ~ C l}$ \\
\hline *EMT, invasive front & 0.036 & 1.54 & $1.03-2.31$ \\
Lymphovascular invasion & 0.963 & 1.01 & $0.58-1.78$ \\
Perineural invasion & 0.010 & 2.58 & $1.25-5.34$ \\
Lymphocyte infiltration & 0.696 & 0.92 & $0.60-1.41$ \\
Tumor growth type & 0.119 & 1.73 & $0.87-3.44$ \\
Tumor budding ( $\geq 10 / \times 200 H P F)$ & 0.778 & 0.90 & $0.60-1.41$ \\
AJCC stage & 0.001 & 1.84 & $1.26-2.68$ \\
\hline
\end{tabular}

*EMT included the expressions of E-cadherin and S100A4.

survival in CRC $[8,20,21]$. In this study, loss of E-cadherin at the invasive margin of CRCs was associated with high tumor budding, perineural invasion, and a poor prognosis.

S100A4 is localized in the nucleus, cytoplasm, and extracellular space and has a wide range of biological functions ranging from regulation of angiogenesis to cell survival,

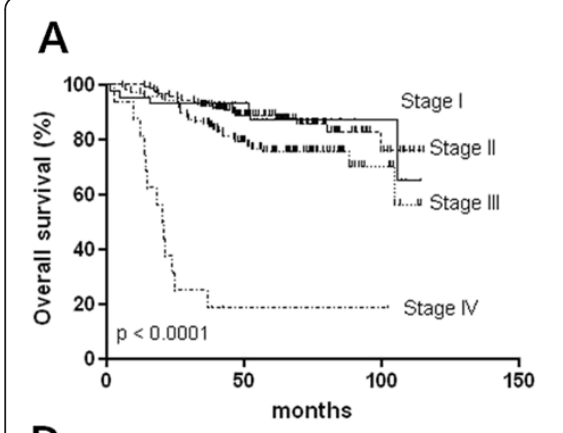

D

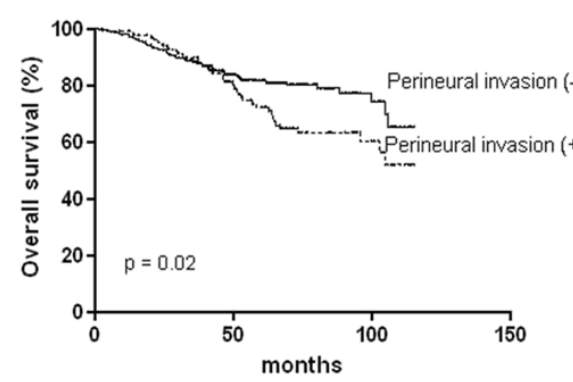

G

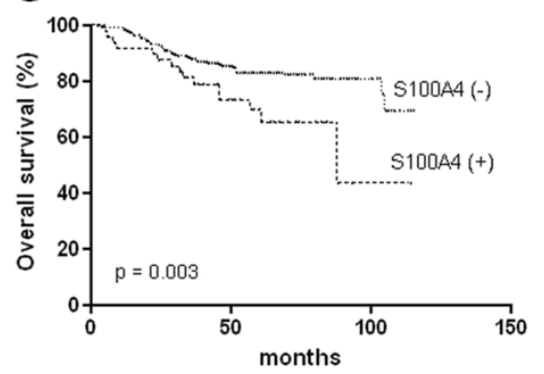

\section{B}

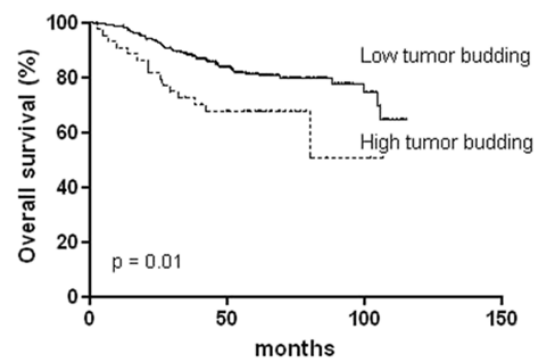

E

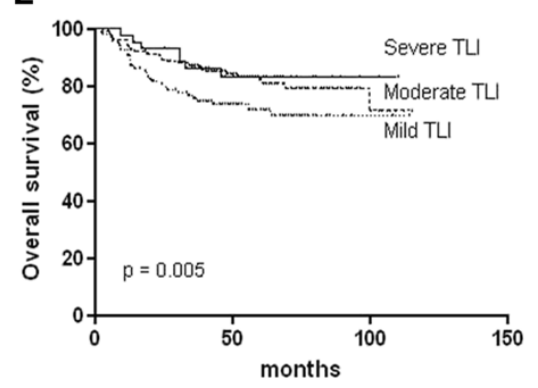

$\mathrm{H}$

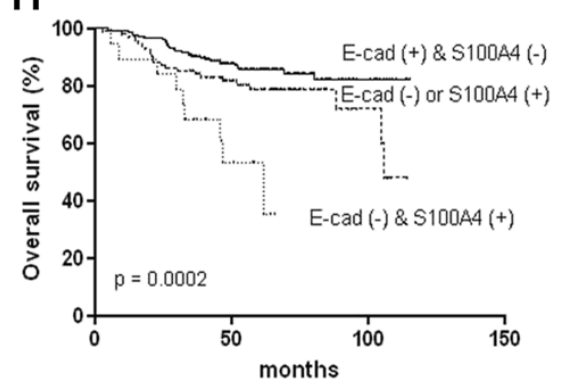

C

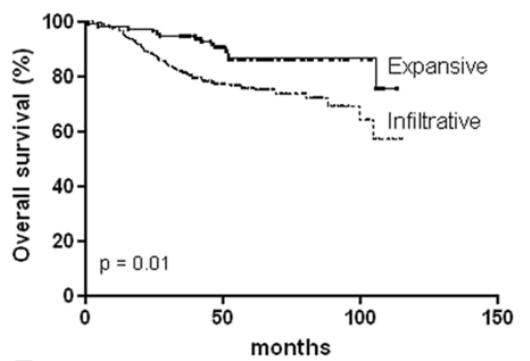

F

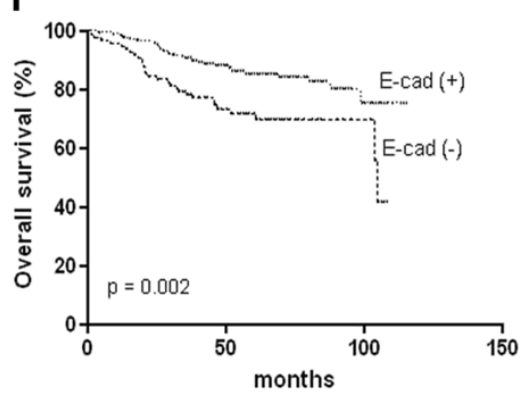

Figure 4 Analysis of overall survival time according to histopathologic parameters and EMT related protein expression. AJCC stage (A), tumor budding (B), type of tumor growth (C), Perineural invasion (D), Peritumoral lymphocytic infiltration (TLI) (E), E-cadherin expression (F), S100A4 expression $(\mathbf{G})$, and combination of E-cadherin and S100A4 (H). 
motility, and invasion [14]. We found that S100A4 expression in the invasive margin was increased in infiltrative tumors, those with a lymph node metastasis, advanced AJCC stage, or lymphovascular- and perineural invasion, which are all parameters representing tumor aggressiveness. We demonstrated that high expression of S100A4 is associated with recurrence and mortality. These results were consistent to the previous studies $[15,22,23]$, in which S100A4 is related to a poor prognosis. One study reported that S100A4 is overexpressed in cell populations enriched for stem-like cells, which is associated with Wnt/APC/ $\beta$-catenin signaling pathway and S100A4 worked as $\beta$-catenin/TCF target gene [24]. Inconsistently other results, S100A4 was also related to lymphocyte infiltration, which protects tumor progression and destroys tumor budding. These findings were resulted from that S100A4 expressing fibroblasts, monocytes, macrophages, T lymphocytes, neutrophilic granulocytes, or endothelial cells may be misinterpreted as S100A4 expressing cancer cells [14].

$\beta$-catenin plays to maintain cell-to-cell adhesion along with E-cadherin. However, $\beta$-catenin also acts as a transcription factor in the Wnt signal transduction pathway and Wnt signaling dysfunction leads to the nuclear accumulation of $\beta$-catenin [9]. Several studies have reported that nuclear $ß$-catenin expression in the invasive margin is associated with high tumor budding and poor prognosis [11], whereas other studies did not find such a relationship $[9,12,20]$. In addition, recent study showed that aberrant $\beta$-catenin expression was related to favorable prognosis [13]. We did not find any association between $\beta$-catenin expression and tumor budding or overall survival in our patient cohort. These inconsistencies may result from different CRC subtypes, the existence of more than one type of CRC in a study [25], or different evaluation methods [3]. We showed that $\beta$-catenin nuclear expression was increased in MSS tumors compared to MSI tumors and that it was higher in left CRCs than right CRCs. These results are consistent with those of a previous study [26], which reported that MSI-high, $C p G$ island methylator phenotype (CIMP)-high, and BRAF mutations, which are characteristics of right CRCs, showed an inverse association with cytoplasmic and nuclear $\beta$-catenin expression. MSS and MSI colorectal cancers are increasingly being recognized as distinct entities with significantly different pathological characteristics, behaviors, and prognoses [27]. MSI is associated with significantly lower levels of nuclear B-catenin and impaired EMT than MSS [27]. In agreement with these reports, we found that $44.4 \%$ of MSI-H cases versus $72.4 \%$ of MSS or MSI-L cases were tumor budding positive.

Aberrant expression of E-cadherin, $\beta$-catenin, and S100A4 showed parallel patterns each other. These results suggested that overexpression of S100A4 inhibits E-cadherin expression and $\beta$-catenin plays a role in driving S100A4- dependent EMT induction [14]. Although individual change of E-cadherin and S100A4 was related to patients' prognosis in univariate survival analysis, multivariate Cox analysis revealed that the combination of E-cadherin loss and S100A4 overexpression was the only prognostic factor in addition to AJCC stage, which is still the most important prognostic factor in CRC. These results highlight the fact that multimarker phenotypes rather than single protein are needed in IHC biomarker investigations [3].

Because the tumor biology of the invasive margin is different than that of the tumor center, the patterns of EMT protein expression are expected to be different at the two sites. In this study, EMT-related changes in the expression of E-cadherin, $\beta$-catenin and S100A4 were more severe in the invasive margin than in the tumor center and EMT changes in the invasive margin, but not the tumor center, had prognostic significance.

Tumor budding is a putative hallmark of CRC cell invasion and has previously been shown to be associated with various clinicopathological parameters, including lymph node metastasis, vascular and lymphatic invasion, distant metastasis, local recurrence, and poor outcomes [28]. In this study, high tumor budding was associated with the ratio of metastatic lymph nodes, type of tumor growth, and perineural invasion (data not shown). It has also been classified as an additional prognostic factor. However, our results suggest that the combination of E-cadherin and S100A4 expression at the invasive margin of CRC is superior to tumor budding for predicting prognosis.

The mRNA levels of E-cadherin, $\beta$-catenin, and S100A4 were not found to be associated with histopathological parameters or prognosis in this study. For $\beta$-catenin and S100A4, mRNA levels reflected that of the encoded protein, but this was not the case for E-cadherin. However, the switch in expression from E-cadherin to $\mathrm{N}$ cadherin and the higher expression of $\mathrm{N}$-cadherin in patients with a poor prognosis were demonstrated in this study. Recent study also showed that $\mathrm{N}$-cadherin was highly expressed in type II papillary renal cell carcinomas than type I cancers and type II cancers were related to poor prognosis [29].

In conclusion, our results suggest that aberrant expression of E-cadherin and S100A4 in the invasive margin was well related with clinicopathological parameters and IHC of both proteins is useful marker to predict prognosis in CRC.

\section{Abbreviations}

AJCC: American Joint Committee on Cancer; CRC: Colorectal cancer; EMT: Epithelial-to-mesenchymal transition; GAPDH: Glyceraldehyde-3phosphate dehydrogenase; IHC: Immunohistochemistry; H\&E: Hematoxylin and eosin; MSI: Microsatellite instability; MSS: Microsatellite stable; TLI: Peritumoral lymphocyte infiltration; TMA: Tissue microarray.

\section{Competing interests}

The authors declare that they have no competing interests. 


\section{Authors' contributions}

S-JL contstructed the manuscript. SYC and RS carried out pathologic study. W-JK checked mRNA levels. MJ constructed tissue microarray. T-GL, B-RS, SMY, and SJY were responsible for clinical data. SMP designed and constructed manuscript. All authors read and approved the final manuscript.

\section{Acknowledgements}

This study was supported by a grant from the National R\&D Program for Cancer Control, Ministry of Health and Welfare, Republic of Korea (1120330).

\section{Author details}

'Department of Surgery, Chungbuk National University College of Medicine and Medical Research Institute, Cheongju, Chungbuk 361-763, Republic of Korea. ${ }^{2}$ Department of Pathology, Chungbuk National University College of Medicine and Medical Research Institute, Cheongju, Republic of Korea. ${ }^{3}$ Department of Urology, Chungbuk National University College of Medicine and Medical Research Institute, Cheongju, Republic of Korea. ${ }^{4}$ Department of Internal Medicine, Chungbuk National University College of Medicine and Medical Research Institute, Cheongju, Republic of Korea. ${ }^{5}$ Department of Laboratory Medicine, Chungbuk National University College of Medicine and Medical Research Institute, Cheongju, Republic of Korea.

Received: 20 February 2013 Accepted: 21 May 2013

Published: 19 June 2013

\section{References}

1. Jung KW, Park S, Kong HJ, Won YJ, Lee JY, Seo HG, Lee JS: Cancer statistics in Korea: incidence, mortality, survival, and prevalence in 2009. Cancer Res Treat 2012, 44:11-24

2. Tsai HL, Chu KS, Huang YH, Su YC, Wu JY, Kuo CH, Chen CW, Wang JY: Predictive factors of early relapse in UICC stage I-III colorectal cancer patients after curative resection. J Surg Oncol 2009, 100:736-743.

3. Zlobec I, Lugli A: Prognostic and predictive factors in colorectal cancer. J Clin Pathol 2008, 61:561-569.

4. Zlobec I, Molinari F, Martin V, Mazzucchelli L, Saletti P, Trezzi R, De Dosso S, Vlajnic T, Frattini M, Lugli A: Tumor budding predicts response to anti-EGFR therapies in metastatic colorectal cancer patients. World J Gastroenterol 2010, 16:4823-4831.

5. Prall F: Tumour budding in colorectal carcinoma. Histopathology 2007, 50:151-162.

6. Zlobec I, Lugli A: Epithelial mesenchymal transition and tumor budding in aggressive colorectal cancer: tumor budding as oncotarget. Oncotarget 2010, 1:651-661.

7. Kalluri R, Neilson EG: Epithelial-mesenchymal transition and its implications for fibrosis. J Clin Invest 2003, 112:1776-1784.

8. Elzagheid A, Buhmeida A, Laato M, El-Faitori O, Syriänen K, Collan Y, Pyrhönen S: Loss of E-cadherin expression predicts disease recurrence and shorter survival in colorectal carcinoma. APMIS 2012, 120:539-548,

9. Brabletz T, Jung A, Hermann K, Gu"nther K, Hohenberger W, Kirchner T: Nuclear overexpression of the oncoprotein b-catenin in colorectal cancer is localized predominantly at the invasion front. Pathol Res Pract 1998, 194:701-704.

10. Sánchez-Tilló E, De Barrios O, Siles L, Cuatrecasas M, Castells A, Postigo A $\beta$-catenin/TCF4 complex induces the epithelial-to-mesenchymal transition (EMT)-activator ZEB1 to regulate tumor invasiveness. Proc Natl Acad Sci U S A 2011, 108:19204-19209.

11. Baldus SE, Mönig SP, Huxel S, Landsberg S, Hanisch FG, Engelmann K, Schneider PM, Thiele J, Hölscher AH, Dienes HP: MUC1 and nuclear B-catenin are coexpressed at the invasion front of colorectal carcinomas and are both correlated with tumor prognosis. Clin Cancer Res 2004, 10:2790-2796

12. Horkko TT, Klintrup K, Makinen JM, Napankangas JB, Tuominen HJ, Makela J, Karttunen TJ, Makinen MJ: Budding invasive margin and prognosis in colorectal cancer-no direct association with beta-catenin expression. Eur J Cancer 2006, 42:964-971.

13. Wangefjord S, Brändstedt J, Ericson Lindquist K, Nodin B, Jirström K, Eberhard J: Associations of beta-catenin alterations and MSI screening status with expression of key cell cycle regulating proteins and survival from colorectal cancer. Diagn Pathol 2013, 8:10.

14. Boye K, Maelandsmo GM: S100A4 and metastasis: a small actor playing many roles. Am J Pathol 2010, 176:528-535.
15. Flatmark K, Pedersen KB, Nesland JM, Rasmussen K, Aamodt G, Mikalsen S-O, Bjørnland K, Fodstad $\varnothing$, Mælandsmo GM: Nuclear localization of the metastasis-related protein S100A4 correlates with tumour stage in colorectal cancer. J Pathol 2003, 200:589-595.

16. Gongoll S, Peters G, Mengel M, Piso P, Klempnauer J, Kreipe H, Von Wasielewski R: Prognostic significance of calcium binding protein S100A4 in colorectal cancer. Gastroenterology 2002, 123:1478-1484.

17. Asayama Y, Taguchi Ki K, Aishima Si S, Nishi H, Masuda K, Tsuneyoshi M: The mode of tumour progression in combined hepatocellular carcinoma and cholangiocarcinoma: an immunohistochemical analysis of E-cadherin, alpha-catenin and beta-catenin. Liver 2002, 22:43-50

18. Zlobec I, Lugli A, Baker K, Roth S, Minoo P, Hayashi S, Terracciano L, Jass JR: Role of APAF-1, and peritumoral lymphocytic infiltration in tumour budding in colorectal cancer. J Pathol 2007, 212:260-268.

19. Karamitopoulou E, Zlobec I, Patsouris E, Peros G, Lugli A: Loss of E-cadherin independently predicts the lymph node status in colorectal cancer. Pathology 2011, 43:133-137.

20. Roca F, Mauro LV, Morandi A, Bonadeo F, Vaccaro C, Quintana GO, Specterman S, De Kier Joffé EB, Pallotta MG, Puricelli LI, Lastiri J: Prognostic value of E-cadherin, beta-catenin, MMPs (7 and 9) and TIMPs (1 and 2) in patients with colorectal carcinoma. J Surg Oncol 2006, 93:151-160.

21. Ngan CY, Yamamoto H, Seshimo I, Ezumi K, Terayama M, Hemmi H, Takemasa I, Ikeda M, Sekimoto M, Monden M: A multivariate analysis of adhesion molecules expression in assessment of colorectal cancer. J Surg Oncol 2007, 95:652-662.

22. Boye K, Nesland JM, Sandstad B, Mælandsmo GM, Flatmark K: Nuclear S100A4 is a novel prognostic marker in colorectal cancer. Eur J Cancer 2010, 46:2919-2925.

23. Kho PS, Jankova L, Fung CL, Chan C, Clarke C, Lin BP, Robertson G, Molloy M, Chapuis PH, Bokey EL, Dent OF, Clarke S: Overexpression of protein S100A4 is independently associated with overall survival in stage $C$ colonic cancer but only in cytoplasm at the advancing tumour front. Int J Colorectal Dis 2012, 27:1409-1417.

24. Stein U, Arlt F, Walther W, Smith J, Waldman T, Harris ED, Mertins SD, Heizmann CW, Allard D, Birchmeier W, Schlag PM, Shoemaker RH: The metastasis-associated gene S100A4 is a novel target of beta-catenin/ T-cell factor signaling in colon cancer. Gastroenterology 2006, 131:1486-1500.

25. lacopetta B: Aberrant DNA methylation: have we entered the era of more than one type of colorectal cancer? Am J Pathol 2003, 162:1043-1045.

26. Kawasaki T, Nosho K, Ohnishi M, Suemoto Y, Kirkner GJ, Dehari R, Meyerhardt JA, Fuchs CS, Ogino S: Correlation of beta-catenin localization with cyclooxygenase-2 expression and CpG island methylator phenotype (CIMP) in colorectal cancer. Neoplasia 2007, 9:569-577.

27. Pino MS, Kikuchi H, Zeng M, Herraiz MT, Sperduti I, Berger D, Park DY, lafrate AJ, Zukerberg LR, Chung DC: Epithelial to mesenchymal transition is impaired in colon cancer cells with microsatellite instability. Gastroenterology 2010, 138:1406-1417.

28. Wang LM, Kevans D, Mulcahy H, O'Sullivan J, Fennelly D, Hyland J, O'Donoghue D, Sheahan K: Tumor budding is a strong and reproducible prognostic marker in T3NO colorectal cancer. Am J Surg Pathol 2009, 33:134-141.

29. Ludwig BC, Bernhard H, Arne S, Heinz-Joachim R, Felix B: N-cadherin is differentially expressed in histological subtypes of papillary renal cell carcinoma. Diagn Pathol 2012, 7:95.

doi:10.1186/1746-1596-8-99

Cite this article as: Lee et al:: Combined aberrant expression of E-cadherin and S100A4, but not $\beta$-catenin is associated with disease-free survival and overall survival in colorectal cancer patients. Diagnostic Pathology 2013 8:99. 